also penetrated the diaphragm, and death has resulted from peritonitis. Allowance may not always be made for the convexity of the diaphragm, and in the multitude of cases calling for the surgeon's attention in hospitals in the field, but little time is given to autopsics. Truly yours, George Derby,

"Cony" U. S. Gen. Hospital, Augusta, Me., March 12, 1865.

\title{
PATHOLOGY AND THERAPEUTICS OF ACUTE CATARRH OF THE BIAADDER.
}

By Herman Zerger, Professor at tue University of Vienna.

[Translated for the Boston Medical and Surgical Journal, from a pamphlet issued in 1863.]

Tue bladder is, owing to its position as an intermediate organ between the ureters and the urethra on the one side, and by its connection with the prostate on the other, subjected, outside of its idiopathic affections, to numerous diseases transmitted from neighboring organs.

There is also a difference to be recognized between the catarrhal affections of the bladder, as idiopathic and as arising from transmission. As to what relates to extension or transmission of the catarrhal affection of the bladder, we learn by experience that catarrh of the bladder arises in most cases through participation with the catarrhal affection of the urethra, and less frequently from affections of the other pelvic organs.

We desire in this article to confine ourselves principally to that catarrhal affection of the bladder which is dependent upon a similar affection of the urethra. Clinical experience teaches that gonorrhoea leads frequently to disease of the bladder. Gencrally, the bladder becomes affected in consequence of gonorrhoea when this discase has attacked the posterior portion of the canal or affected the prostate. Such are the well-known cases usually designated as clironic or secondary gleet. $A s$ it is generally only after weeks duration of gonorrhoea that the portion of the urcthra nearest the bladder becomes affected, so a similar interval occurs before the bladder becomes diseased. There are cases, however, where only a few days after the commencement of the gonorrhœa a catarrhal affection of the bladder is established. Before we begin a more precise description of the semiotics of this disease of the bladder, it is nocessary to observe that the disease does not affect the entire surface of the bladder, but only the so-called neck. 'The indications that only this portion of the bladder is sympathetically aflected, are given by a remarkable functional disturbance of the organ. Micturition becomes extremely painful, and is often so distressing that, under the violent tenesmus, the patient is obliged frequently to micturate every ten minutes. If he yields to this desire, he generally passes only a 
few drops of a very acid urine. Should every single drop cause pain as it leaves the bladder, the last will be of such a violent kind that, as the patient expresses himself, it seems as if the penis became spasmodically drawn back against the os pubis, so as to be in a half erect condition.

The passing of the few drops of urine proceeds so slowly that patients sometimes involuntarily pass the urine in bed. Should this complaint be not properly recognized, the patient becomes subject to disturbance of the digestive organs, accompanied by fever and other severe symptoms, which cause great alarm to him and to the inexperienced physician. Up to this time the small quantity of urine passed continues clear, and only after long standing shows a sediment of epithelium and mucus; but at a later period it shows a small quantity of blood, usually forced, after the urine has passed, in a few drops from the bladder. This hamaturia is caused by the protecting epithelium becoming separated from the inflamed mucous coat of the neck of the bladder, so that the capillaries are laid bare and subjected to forced straining of the neck, by which bleeding is produced. If, under this condition, we examine more carefully, we find that the abundant muco-purulent secretion which was first formed has considerably diminished, and has yielded to a more serous discharge. It produces at the mouth of the urethra, when the patient has been able for some time to resist the desire to urinate, a sticky serous secretion, similar to that observed in a violent catarrhal affection of the mucous membraue of the nose. If we examine the body of the bladder above the os pubis, it presents no sensitiveness to pressure even with considerable force; a digital examination per rectum, although no enlarged prostate can be felt, will produce intolerable suffering by pressure upon the sensitive portion of the urethra. From such an examination one has the right to conclude that the entire surface of the bladder is not affected, but only the forward part-that is, the neek.

As we have already remarked, clear urine, or at most presenting but a few drops of blood, will always be passed during the catarrhal affection of the neck of the lladder, in spite of the riolent tenesmus. It therefore happens, as the discase advances over the entire mucous coat of the bladder, that before the first drop of urine passes blood has already preceded it. It is natural, therefore, that the urine which passes afterwards should be no longer clear, but turbid by means of this bloody muco-purulent secretion. As is well known, the mucous secretion of the bladder causes fermentation in the urine; carbonate of ammonia, therefore, becomes developed in the bladder, and in such cases will give the urine an alkaline re-action.. At this stage of the catarrh, so far as intensity is concerned, an increase of the disease is possible. Although the urine, after cooling, precipitates up to this time only a muco-purulent sediment, this will, by the further progress and continued separation of the mucous lining, reach such 
a state as to fill the urine with lumps of pus, mucus and blood. The muco-purulent deposit in the urine during the extreme stage of the disease, presents a flocculent or jelly-like condition-an appcarance which is produced by the carbonate of ammonia formed in the urine, with tho pus and mucous secretions. If we pour ammonia orer pus and mucus, wo produce a similar stringy, jelly-like substance. While the urine in the carlier stages produces an alkaline re-action, it will, after standing some time, give off a disagrecable, ammoniacal odor. It gives off, in those cases where the affection of the bladder has reached the last-mentioned stage, even when just passed, such an am. moniacal smell that one is justified in supposing that it is undergoing a foul fermentation in the bladder. This last condition, usually de. nominated blennorrhoea of the bladder, is a less frequent result of blennorrhoe of the urethra, but is more commonly attendant upon a 'violent stricture of the urethra which has had its origin in a blennorrhœa of that canal. While the two earlier stages of this affection of the bladder depend only upon a transmitted pathological change in the mucous membrane of the bladder, the blennorrhoea produces such an hypertrophy of the muscular coat that the single bundles of fibres have the appearance of the columne carncx of the heart-a condition called by the French "la ressic à colonne." So long as the neck of the bladder is alono affected, so long is the anatomical change of the mucous parts scarcely to bo percelved; but when the affection extends to the entire mucous membrane of the bladder, an anatomical change occurs in the mucous and muscular coats which can nerer be entirely removed, and which leads to a permanent functional disturbance of this organ. We therefore may consider the catarrhal affoction of the neck of tho bladder as an acute catarrh of the bladder; while in the affection of the entire thickness, the musoles become involved and tho discase takes on a chronic character. 'The ordinary duration of the catarrh of the bladder contracted from a blonnorrhoea of the urethra is, under proper care, from eight to twelve days; but may, however, under certain conditions, continue much longer, if by some accident or injurious influence a renewal of the inflammation takes place. 'This may be caused by hæmorrhoids, from the proximity of the branches of veins and the venous network which surrounds the bladder and rectum. And as it may be caused by hæmorrhoids, so may it arise from a passire hyperxmia of the bladder.

Canses of the Acute Catarth of the Bladder.-As already mention. cd, the acute catarrh of the bladder arisos from an cxtension of a blennor'shea of the urethra to the bladder. There are, however, influences which are more less favorable to the further extension of the disease. Such are the llinking of new, unfermented beer, must, or champagne wine. The too froquent drinking of soda-water, which has of late years become so fashionable, is also injurious. Experience has taught us that the use of fermenting drinks has an injurious 
effect upon the neck of the bladder of even healthy persons. There are well-known cases of numerous individuals who, after drinking a badly fermented beer, have been seized with dysuria, at times amounting to ischuria. Some hours after partaking such drinks, these individuals have the continual desire to pass urine, which, coming away only by drops, shows, after cooling, a mucous precipitate. Often in those districts where, during the autumn, the apple must is drunk in the greatest quantity, the larger part of the younger male portion of the villagers become affected in this manner. With us here in Austria, where great quantities of apple must and apple wine are likewise drunk, it has commonly been known as the cider dis. ease. Next to the above-mentioned drinks, there are certain medici. nal injections which I believe may develope an acute catarrh of the bladder; as, for example, the use of terra catechu or sanguis draconis in the acute stages of the blennorrhoea of the urethra. Some wellskilled medical authors claim to have seen a similar injurious influence from injections of copaiba and cubebs. I cannot conceive myself, as yet, of such a thing, although I remember seeing in one case an inflammatory condition of the neck of the bladder coming on after an injection of balsam of copaiba. I can, however, conceive that by an unskilful injection, with only a half-filled syringe, by which air may be forced into the bladder, tenesmus may be produced which may cause all the symptoms of an acute catarrh of the bladder.

Very frequently an acute catarrh of the bladder is produced by the passing of catheters and bougies. It has long been known that the neck of the bladder, and likewise the verumontanum or colliculus seminalis, is the most sensitive part of the urinary apparatus. And it happens not unfrequently that the strongest man faints from an intense pain caused by the passing of the instrument over the caput gallinaginis. If the surrounding parts are besides already inflamed, as by an extended blennorrhoea of the urethra, it is extremely easy to make the catarrhal affection worse by an instrumental excitant. Coitus during gonorrhoea will frequently be punished by an acute catarrh of the bladder. A forced ride will likewise produce it, by injury to the prostate.

Prognosis of Acute Catarrh of the Bladder.-Acute catarrh of the bladder will, with proper care, when it arises from gonorrhoca, be cured; disappearing with the last sign of the gleet. Not unfrequently does the catarrh extend to the seminal canal, producing a catarrh, or an epididymitis. If the acuto condition returns frequently, it is apt to produce locally a permanent change; not unfrequently a permanent growth of the point of the trigonus lientandi, or la luette vesicalc of Amussat, which may prevent the passing of the secretions. More frequently than this, according to my knowledge, is a diseased condition very seldom spoken of by authors, namcly, a permanent hyperamia of the colliculus seminalis, which is noticed during the life of the patient at the moment of ejaculation during sexual excitement, by VoL. LXXII.-No. 9* 
an intense pain, as if a heated needle were passed through the perinæum. In other cases the catarrhal process extends merely to the vesiculæ seminalis, causing such a relaxation of them that the accumulated semen becomes forced out, by the slightest pressure by the contents of the rectum, through the urethra (spermatorrhœa). The catarrhal process extends itself at times to the outlet of the prostate, so that several of them will continually throw off its peculiar secretion mixed with nucus, which will be passed by the urine in the form of a stringy secretion. Although as a rulc, as has already been said, tho acute catarrh passes off without any particular injury, it unay, at times, produce cxtremely unpleasant consequences.

'Therapuentics.-In the treatment of acute vesical catarrh, rest and a proper dict are of paramount importance. The patient should remain in his room, even if he is not obliged to keep his bed. An equable temperature is necessary, that a part of the aqueous secretion may pass off by the skin that otherwiso would have to pass by the urethra. The dict must be regulated according to the degree of fever. Should there be considerable fever, the patient should be restricted to a soup dict. For drink, the patient should take decoctum seminum lini or an emulsion of canabina, with or without syrup diacodii. We cannot say, however, whether any of these oleaginous or mucilaginous substances pass into the urine or not. Their influence may be merely to make the urine more watery. The principal object in the trcatment is, to relieve the patient from the inces. sant desire to micturate; this is more properly effected by the administering of an anodyne, either inwardly or topically; and for this purpose we cannot do better than to uso opium or morphia--constipation being carefully guarded against, as every passage of frecs by an inflamed prostate is to the patient extremely painful. In order to diluto the urine of the patient, and to introduce a narcotic into the system, we have succeeded for years by the use of herba herniaria glabre, a plant which without any good reason has become almost entirely obsoletc. This plant belongs to the papilionacex, and grows wild with us. It is a mild diuretic, and contains a narcotic principle, which I can bear witness lias almost a specific influence upon the sphincter muscles, without paralyzing or obstructing their action. A similar, although weaker drug is the chenopodium ambrosoides; and I prescribe for such affections the following:17. Herniaria glabræe, chenopodii ambrosidis, aa. dr. tres. Div. in doses aq. No. viij. One of these portions should be infused in a sauccrful of boiling water, to which milk and sugar may bo added.

When it is possible, we poultice the perinwum and those parts in the neighborliood of the bladder. After a moderate quantity of the tea has been taken, the urination becomes remarkably casier. By way of a parenthesis, we would remark that we cannot recommend this plant too highly in chrouic catarrh also. We can, as we havo said already, assist the action of the herniaria by topical narcotics; for 
which purpose we may apply a cataplasm of cicuta, and in urgent cases a suppository of the extract of belladonna as follows:- $\mathbf{R}$. Ext. belladonnæ, gr. i.; butyr. simpl. et butyr. de cacao, aa 3 ss. M. Ft. suppositoria, No. iv. One of these is to be carcfully passed up the rectum morning and evening. If there should be constipation for sercral days, I generally give a clyster of ol. ricini. If at times painful excretions take place, we must try to obviate them by lukewarm cataplasms of conium. Should retention of urine occur, we must try to overcome it, if possible, without long delay, by introducing a conical moderate-sized clastic catheter with a bulb upon its end. The catheter should be well oiled before passing, and should be allowed to remain in the bladder for half an hour. The so called bougies a demeure are very seldom borne by the patient in this case. Before I close, I feel it my duty to call attention to what has almost become a traditional misconception of the treatment of this discase in medicine. In most text books, chronic catarrh of the bladder is in most cases treated after one rule; namely, by the use of potassa or kali carb. either in the form of a solution or soda water. My experience teaches me to speak decidedly against this custom. I have shown that similar diseased conditions are frequently produced by the partaking of beer, must, \&c. The explanation of their action may be found in the laws of Wöhler, as where alkaline salts or acetate of potash are introduced into the blood, they become transformed into a carbonic oxyde, which I believe to be the injurious element in the above-mentioned drinks, and which would be increased by the addition of these carbonates; as I have seen a decided tendency to grow worse with such patients in my practice where carbonic acid drinks were administered. Equally unprofitable is the use of the decoction fol. uvæ-ursi and all other astringent medicines in the acute catarrh of the bladder. All such medicines containing carbonic acids, and the mineral waters of Preblau, Gioshübel, Franz-bad, Güstein, Karlsbad, \&c., are to be kept from such patients as are affected with chronic catarrh of the bladder.

\section{FATAL CASE OF DIPHTHERIA BY INOCULATION.}

[Communlcated for the Boston Medical and Surgical Journal.]

IN the latter part of last summer, I was called to Washington Centre, six miles distant, to risit W. B. S- a.t. 30 , lawyer by profession-and from him learned the following facts:-His sister had recently died of a very malignant typo of diphtheria, in the neighboring town of Stoddard. She was sick but a few days, and during this time Mr. S. assisted in taking care of her. A few hours before her death, she vomited, and a portion of the matter ejected from her stomach came in contact with an abraded surface upon one of his fingers. This occurred on the 25th of August, I think. No notice 